\title{
Methylome analysis and whole-exome sequencing reveal that brain tumors associated with encephalocraniocutaneous lipomatosis are midline pilocytic astrocytomas
}

\author{
Elvis Terci Valera ${ }^{1,2} \cdot$ Melissa K. McConechy ${ }^{2}$. Tenzin Gayden ${ }^{3}$ - Barbara Rivera ${ }^{2}$. David T. W. Jones ${ }^{4}$. \\ Andrea Wittmann ${ }^{4} \cdot$ HyeRim Han $^{2}$ - Eric Bareke ${ }^{5} \cdot$ Hamid Nikbakht $^{5} \cdot$ Leonie Mikael $^{3} \cdot$ Rosane Gomes Queiroz $^{1}$. \\ Veridiana Kiill Suazo ${ }^{1}$. Ji Hoon $\mathrm{Phi}^{6} \cdot$ Seung-Ki Kim ${ }^{6}$. Sung-Hye Park ${ }^{7} \cdot$ Raita Fukaya $^{8,9} \cdot$ Mi-Sun Yum ${ }^{10}$. \\ Tae-Sung Ko ${ }^{10}$. Ricardo Santos de Oliveira ${ }^{11}$. Helio Rubens Machado ${ }^{11}$. María Sol Brassesco ${ }^{12}$. \\ Antonio Carlos do Santos ${ }^{13}$. Gustavo Novelino Simão ${ }^{13}$. Leandra Náira Zambelli Ramalho ${ }^{14}$. Luciano Neder $^{14}$. \\ Carlos Alberto Scrideli ${ }^{1} \cdot$ Luiz Gonzaga Tone $^{1} \cdot$ Jacek Majewski ${ }^{2,5} \cdot$ Nada Jabado $^{2,3}$
}

Received: 25 April 2018 / Revised: 9 August 2018 / Accepted: 9 August 2018 / Published online: 24 August 2018

(c) The Author(s) 2018

Keywords Encephalocraniocutaneous lipomatosis $\cdot F G F R 1 \cdot$ RASopathies, genetics, brain tumors $\cdot$ Children

\section{Introduction}

Encephalocraniocutaneous lipomatosis (ECCL; [MIM:613001]) is a rare sporadic RASopathy due to one of two mutually exclusive fibroblast growth factor receptor 1 (FGFR1) mutations p.N546K or p.K656E. These activating hotspot mutations are identified in affected tissues, but not in the peripheral blood of ECCL patients, and are likely the result of post-zygotic constitutional mosaicism promoting locally constitutive activation of the RAS-MAPK pathway [1]. The same FGFR1 mutations occur in subgroups of sporadic low-grade gliomas (LGG) $[7,10,12]$ indicating probable intersection between ECCL and tumorigenesis, possibility further substantiated by reports of brain tumors in nine ECCL cases with wide-ranging histopathological subtypes $[1-3,5,6,8,9,13]$.

Elvis Terci Valera, Melissa K. McConechy and Tenzin Gayden contributed equally.

Luiz Gonzaga Tone, Jacek Majewski and Nada Jabado are cosenior authors.

Electronic supplementary material The online version of this article (https://doi.org/10.1007/s00401-018-1898-8) contains supplementary material, which is available to authorized users.

Elvis Terci Valera

valeraet@gmail.com

Nada Jabado

nada.jabado@mcgill.ca

Extended author information available on the last page of the article
To evaluate the pathological and genetic landscape of these brain tumors in ECCL, we acquired five of these cases (Suppl. Table 1 Online Resource 1 and 4), representative H\&E and MRI for each provided in Suppl. Fig. 1 (Online Resource 3). Four were originally reported as LGG, either pilocytic astrocytomas (PA) (ECCL1, ECCL2) [3, 13], papillary glioneural tumor (PGNT) (ECCL3) [9], or dysembryoplastic neuroepithelial tumor (DNET) (ECCL5) [6], while ECCL4 was reported as a glioblastoma [5]. Blinded histopathological review resulted in re-classification of the PGNT/ECCL3 as a pilomyxoid astrocytoma (PMA), and the DNET/ECCL5 as PA. DNA methylation analysis [4] using hierarchical clustering and t-SNE analysis with 75 reference cases representing nine tumor subclasses [11] revealed that three out of five tumors are midline PAs, and subcluster with FGFRI-mutated midline PAs (Fig. 1a; Suppl. Fig. 2 Online Resource 3): ECCL1 and ECCL2 showed high classifier scores for PA (0.98 and 1.00, respectively). ECCL3 had a low score (0.09) likely due to normal tissue, but still reliably clustered with PAs. ECCL4 clustered with the rare subgroup of recently described methylation class anaplastic astrocytoma with piloid features (MC-AAP) [11], a classification further substantiated by the $C D K N 2 A / B$ deletion identified in this sample (Suppl. Fig. 3 Online Resource 3). ECCL5 received the highest methylation classifier score for PA (0.43). Hierarchical clustering further suggested an FGFRI-mutated midline PA, while on t-SNE analysis, this tumor resembled DNETs (Suppl. Fig. 2 Online Resource 3), mirroring the histological dilemma between DNET and 


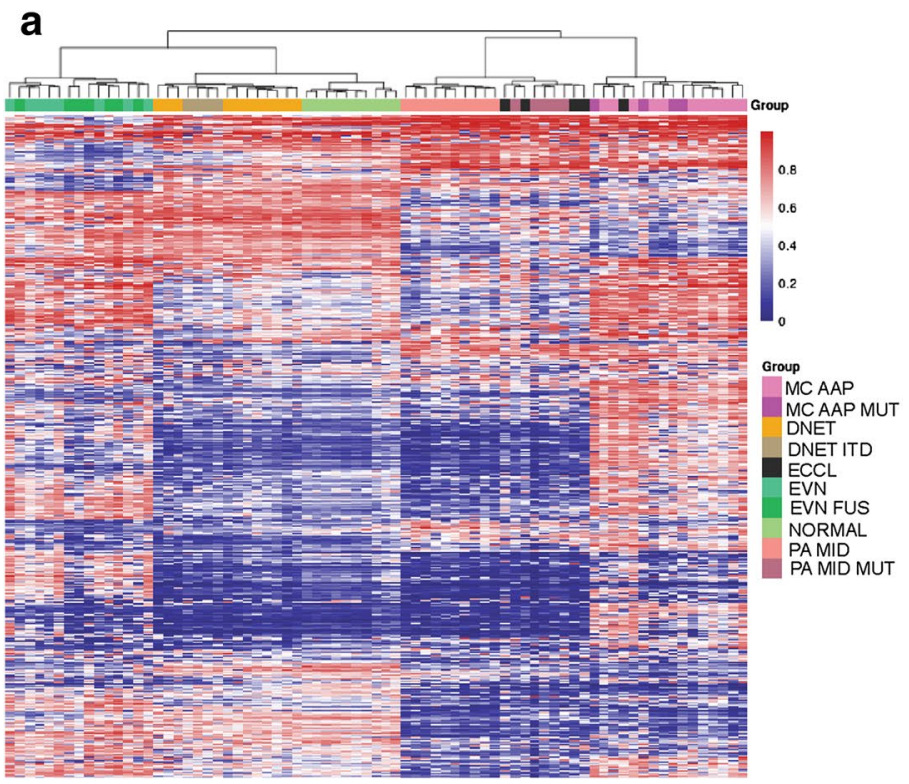

b

\begin{tabular}{|c|c|c|c|c|c|}
\multicolumn{2}{c}{ ECCL1 } & \multicolumn{1}{c}{ ECCL2 } & \multicolumn{1}{c}{ ECCL3 } & \multicolumn{1}{c}{ ECCL4 } & ECCL5 \\
\hline Age/Sex & $3.8 / \mathrm{M}$ & $10 / \mathrm{F}$ & $7 / \mathrm{F}$ & $32 / \mathrm{F}$ & $8 / \mathrm{F}$ \\
\hline Methylation Class & & & & & \\
\hline FGFR1 K656E & & & & & \\
\hline FGFR1 N546K & & & & & \\
\hline FGFR1 V561M & & & & & \\
\hline FGFR1 K656N & & & & & \\
\hline PTPN11 E69K & & & & & \\
\hline KRAS Q51H & & & & & \\
\hline NF1 K2375N & & & & & \\
\hline ATRX Q254X & & & & & \\
\hline CDKN2A/B deletion & & & & & \\
\hline & \\
\hline
\end{tabular}

Fig. 1 DNA methylation classification and mutations identified in five ECCL-associated brain tumors. a Hierarchical clustering of methylation data from five ECCL tumors (black) with 75 reference cases of nine established glioma methylation classes indicated by different colors. Reference classes: MC-AAP methylation class anaplastic astrocytoma with piloid features; MC-AAP MUT with FGFRI mutation; DNET dysembryoplastic neuroepithelial tumor; DNET

PA for this tumor, two entities of the spectrum of FGFRImutant brain tumors.

Whole-exome sequencing on these five tumors and matched peripheral blood available from three patients (ECCL1, 2, 4) identified FGFR1 K656E (ECCL1, ECCL2) and FGFR1 N546K (ECCL3, ECCL4, ECCL5) (Suppl. Fig. 4 Online Resource 3, Suppl. Table 2 Online Resource 2). All five tumors showed additional concurrent alterations in FGFR1/RAS/MAPK pathway genes, including $N F 1$, KRAS, PTPN11, and FGFR1 mutations (Fig. 1b). Two cases harbored a second mutation in FGFRI: ECCL3 had confirmed in cis FGFR1 N546K/K656N mutations (Suppl. Fig. 5 Online Resource 3); ECCL1 had concurrent somatic FGFR1 K656E/V561M mutations possibly also in cis based on a previous report of similar in cis FGFRl combination in an ECCL PA [1], even if we could not confirm this due to unavailability of material. ECCL2 had PTPN11 E69K and ECCL5 KRAS Q61H mutations, both previously identified in sporadic PAs [11, 14]. Also, co-occurence of FGFR1/PTPN11 mutations has been described in a small subset of PAs [7]. In ECCL4, we identified two additional somatic NF1 K2375N and ATRX Q254X mutations (Fig. 1b, Suppl. Table 2 Online Resource 2), a pattern which, in addition to $C D K N 2 B / A$ deletion, the high-grade histological features and older age of ECCL4 is concordant with what has been described in MC-AAPs [11].
ITD internal duplication of $F G F R 1$; EVN extraventricular neurocytoma; EVN FUS with FGFR1:TACC1 fusion; NORMAL normal brain; PA MID midline pilocytic astrocytoma; PA MID MUT with FGFR1 mutation. b Summary of ECCL patient clinical and molecular characteristics. Red boxes indicate presence and gray boxes absence of a given genetic alteration

Finally, somatic mosaicism and non-hereditary nature of FGFRl mutations in ECCL patients and their parents were confirmed in two cases using targeted sequencing. In ECCL1, FGFR1 mutations were absent in blood DNA in the patient and mother (Suppl. Fig. 6 Online Resource 3, Suppl. Table 2 Online Resource 2). In ECCL2, co-occurrence of $F G F R 1$ and PTPN11, mutations were exclusive to the brain tumor while the skin lipoma had only the FGFRl mutation, suggesting the need for a "second hit" in the MAPK pathway in the brain (Suppl. Fig. 6 Online Resource 3).

In summary, integrating histology and molecular data on the largest cohort of ECCL-associated brain tumors assembled to date shows that these are midline PAs. A degree of glioneuronal differentiation may lead to a diagnosis of DNET, while ECCL4 originally diagnosed as glioblastoma would have been diagnosed as MC-AAP based on recent findings. The initial FGFRI mutation requires additional somatic alterations in the FGFR1/RAS/MAPK pathway to drive tumorigenesis towards development of distinct subgroups of PAs in ECCL. Thus, even if additional molecular follow-up studies are needed to confirm these observations, pathogenesis of ECCL-associated PA is possibly distinct from that of sporadic PAs where typically one hit is needed [8]. Moreover, the use of novel therapies targeting FGFR 1 may prove less effective as some of these second hits are downstream of the receptor. In conclusion, our data reinforce 
the acquired genetic trait and mosaic nature of ECCL and further emphasize the need for in-depth molecular analysis to refine and ensure accuracy of pathological diagnosis and clinical decision-making approaches for affected patients.

Acknowledgements We thank Drs Ferracioli-Brandão, Albrecht and Karamchandani for their assistance. E.T.V. has a FAPESP grant (Fundação de Amparo a Pesquisa do Estado de São Paulo-Grant. 2015/20142-0-Brazil) research program abroad (BPE). M.K.M. is supported by a CIHR Banting Postdoctoral Fellowship. Additional fundings: NIH (P01CA196539 to N.J. and J.M.); the Canadian Institutes of Health Research (CIHR/MOP286756 to N.J.), the Fonds de Recherche du Québec-Santé (salary awards A.B., J.P., N.J.) and the Brain Tumour Charity (Everest Centre for Low-Grade Paediatric Brain Tumours to D.T.W.J).

\section{Compliance with ethical standards}

Conflict of interest No competing financial interests.

Open Access This article is distributed under the terms of the Creative Commons Attribution 4.0 International License (http://creativeco mmons.org/licenses/by/4.0/), which permits unrestricted use, distribution, and reproduction in any medium, provided you give appropriate credit to the original author(s) and the source, provide a link to the Creative Commons license, and indicate if changes were made.

\section{References}

1. Bennett JT, Tan TY, Alcantara D, Tetrault M, Timms AE, Jensen D et al (2016) Mosaic activating mutations in FGFR1 cause encephalocraniocutaneous lipomatosis. Am J Hum Genet 98:579_ 587. https://doi.org/10.1016/j.ajhg.2016.02.006

2. Bieser S, Reis M, Guzman M, Gauvain K, Elbabaa S, Braddock SR et al (2015) Grade II pilocytic astrocytoma in a 3-month-old patient with encephalocraniocutaneous lipomatosis (ECCL): case report and literature review of low grade gliomas in ECCL. Am J Med Genet A 167A:878-881. https://doi.org/10.1002/ajmg.a.37017

3. Brassesco MS, Valera ET, Becker AP, Castro-Gamero AM, de Aboim Machado A, Santos AC et al (2010) Low-grade astrocytoma in a child with encephalocraniocutaneous lipomatosis. J Neurooncol 96:437-441. https://doi.org/10.1007/s11060-009-9978-1

4. Capper D, Jones DTW, Sill M, Hovestadt V, Schrimpf D, Sturm D et al (2018) DNA methylation-based classification of central nervous system tumours. Nature 555:469-474. https://doi. org/10.1038/nature26000

5. Fukaya R, Ozaki M, Kamamoto D, Tokuda Y, Kimura T, Fukuchi $M$ et al (2016) Significant antitumor response of disseminated glioblastoma to bevacizumab resulting in long-term clinical remission in a patient with encephalocraniocutaneous lipomatosis: a case report. Mol Clin Oncol 5:417-421. https://doi.org/10.3892/ mco.2016.996

6. Han JY, Yum MS, Kim EH, Hong S, Ko TS (2016) A rare case of dysembryoplastic neuroepithelial tumor combined with encephalocraniocutaneous lipomatosis and intractable seizures. Korean J Pediatr 59:S139-S144. https://doi.org/10.3345/kjp.2016.59.11.S139

7. Jones DT, Hutter B, Jager N, Korshunov A, Kool M, Warnatz HJ et al (2013) Recurrent somatic alterations of FGFR1 and NTRK2 in pilocytic astrocytoma. Nat Genet 45:927-932. https://doi. org/10.1038/ng.2682

8. Kocak O, Yarar C, Carman KB (2016) Encephalocraniocutaneous lipomatosis, a rare neurocutaneous disorder: report of additional three cases. Childs Nerv Syst 32:559-562. https://doi. org/10.1007/s00381-015-2847-7

9. Phi JH, Park SH, Chae JH, Wang KC, Cho BK, Kim SK (2010) Papillary glioneuronal tumor present in a patient with encephalocraniocutaneous lipomatosis: case report. Neurosurgery 67:E1165-E1169. https://doi.org/10.1227/NEU.0b013e3181edb24c

10. Qaddoumi I, Orisme W, Wen J, Santiago T, Gupta K, Dalton JD et al (2016) Genetic alterations in uncommon low-grade neuroepithelial tumors: BRAF, FGFR1, and MYB mutations occur at high frequency and align with morphology. Acta Neuropathol 131:833-845. https://doi.org/10.1007/s00401-016-1539-z

11. Reinhardt A, Stichel D, Schrimpf D, Sahm F, Korshunov A, Reuss DE et al (2018) Anaplastic astrocytoma with piloid features, a novel molecular class of IDH wild type glioma with recurrent MAPK pathway, CDKN2A/B and ATRX alterations. Acta Neuropathol. https://doi.org/10.1007/s00401-018-1837-8

12. Rivera B, Gayden T, Carrot-Zhang J, Nadaf J, Boshari T, Faury D et al (2016) Germline and somatic FGFR1 abnormalities in dysembryoplastic neuroepithelial tumors. Acta Neuropathol 131:847-863. https://doi.org/10.1007/s00401-016-1549-x

13. Valera ET, Brassesco MS, Scrideli CA, de Castro Barros MV, Santos AC, Oliveira RS et al (2012) Are patients with encephalocraniocutaneous lipomatosis at increased risk of developing low-grade gliomas? Childs Nerv Syst 28:19-22. https://doi. org/10.1007/s00381-011-1601-z

14. Zhang J, Wu G, Miller CP, Tatevossian RG, Dalton JD, Tang B et al (2013) Whole-genome sequencing identifies genetic alterations in pediatric low-grade gliomas. Nat Genet 45:602-612. https ://doi.org/10.1038/ng.2611

\section{Affiliations}

Elvis Terci Valera ${ }^{1,2} \cdot$ Melissa K. McConechy $^{2}$ - Tenzin Gayden ${ }^{3}$ - Barbara Rivera ${ }^{2}$ - David T. W. Jones ${ }^{4}$. Andrea Wittmann ${ }^{4} \cdot$ HyeRim Han $^{2}$ - Eric Bareke ${ }^{5} \cdot$ Hamid Nikbakht $^{5}$. Leonie Mikael ${ }^{3}$. Rosane Gomes Queiroz ${ }^{1}$. Veridiana Kiill Suazo ${ }^{1}$. Ji Hoon Phi ${ }^{6}$. Seung-Ki Kim ${ }^{6}$. Sung-Hye Park ${ }^{7}$. Raita Fukaya ${ }^{8,9} \cdot$ Mi-Sun Yum ${ }^{10}$. Tae-Sung Ko ${ }^{10}$. Ricardo Santos de Oliveira ${ }^{11}$. Helio Rubens Machado ${ }^{11}$ - María Sol Brassesco ${ }^{12}$. Antonio Carlos do Santos ${ }^{13}$. Gustavo Novelino Simão ${ }^{13}$. Leandra Náira Zambelli Ramalho ${ }^{14} \cdot$ Luciano Neder $^{14}$. Carlos Alberto Scrideli ${ }^{1} \cdot$ Luiz Gonzaga Tone $^{1} \cdot$ Jacek Majewski ${ }^{2,5} \cdot$ Nada Jabado $^{2,3}$ [D 
1 Department of Pediatrics, Ribeirão Preto Medical School, University of São Paulo, HC Criança-Av. Bandeirantes, 3900, Ribeirão Preto, SP CEP 14048-900, Brazil

2 Department of Human Genetics, McGill University, Montreal, QC, Canada

3 Department of Pediatrics, The Research Institute of the McGill University Health Center, McGill University, Montreal, QC H4A 3J1, Canada

4 Pediatric Glioma Research Group, Hopp Children's Cancer Center, NCT Heidelberg (KiTZ) and German Cancer Research Center (DKFZ), Heidelberg, Germany

5 McGill University and Genome Quebec Innovation Center, Montreal, QC, Canada

6 Division of Pediatric Neurosurgery, Seoul National University Children's Hospital, Seoul, Republic of Korea

7 Department of Pathology, Seoul National University Children's Hospital, Seoul, Republic of Korea
8 Department of Neurosurgery, Shizuoka City Shimizu Hospital, Shizuoka, Japan

9 Department of Neurosurgery, Fuji Hospital, Aichi, Japan

10 Division of Pediatric Neurology, Department of Pediatrics, Asan Medical Center Children's Hospital, University of Ulsan College of Medicine, Seoul, Republic of Korea

11 Division of Pediatric Neurosurgery, Department of Surgery and Anatomy, University Hospital, Ribeirão Preto Medical School, University of São Paulo, Ribeirão Preto, SP, Brazil

12 Department of Biology, Faculty of Philosophy, Sciences and Letters at Ribeirão Preto, University of São Paulo, Ribeirão Preto, SP, Brazil

13 Department of Image Science and Medical Physics Center, Internal Medicine, University of São Paulo, Ribeirão Preto, SP, Brazil

14 Department of Pathology, Ribeirão Preto Medical School, University of São Paulo, Ribeirão Preto, Brazil 